\title{
MÉDICOS Y REDES SOCIALES. MECANISMOS DE PODER DE LA PROFESIÓN MÉDICA EN EL SIGLO XVIII
}

\section{Mercedes Granjel}

Universidad de Salamanca

\begin{abstract}
RESUMEN
Este trabajo analiza de forma global y articulada la identidad social de los médicos que ejercieron en Salamanca a lo largo del siglo XVIII. A través de sus biografías obtenemos perfiles, trayectorias y pautas de comportamiento que ponen de manifiesto la diversidad interna de este colectivo. El estudio de los vínculos familiares, relaciones con las élites locales y las redes sociales tejidas al hilo de sus trayectorias y actividad profesional, nos permite reconstruir el conjunto relacional en que se mueven y verificar su papel en los procesos de ascenso social. Se trata de una propuesta metodológica que conjuga la prosopografía con el análisis de las redes sociales (familia, amistades, clientela), prácticamente inexplorada como instrumento de análisis social de la profesión médica.
\end{abstract}

PALABRAS CLAVE: Profesión médica. Redes sociales. Pacientes. España. Siglo XVIII.

\section{PHYSICIANS AND SOCIAL NETWORKS. POWER MECHANISMS OF THE MEDICAL PROFESSION IN EIGHTEENTH-CENTURY}

\begin{abstract}
The object of the analysis carried out in this paper is a global and descriptive examination of the social identity of the physicians that practiced medicine in Salamanca during the 18th century. Through their biographies we obtain profiles, careers and behavior that confirm the rich diversity of this community. By studying their family ties, their relation with the local elite, and the social networks engaged throughout their lives and careers we may reconstruct the context and dynamics of their relational world and establish their role in the processes of social mobility. The methodological approach set out in this paper combines prosopography and an analysis of the social networks (family, friendship, business), which constitutes an unexplored tool in the social analysis of the medical profession.
\end{abstract}

KEY WORDS: Medical profession. Social networks. Patients. Spain. 18th Century. 


\section{INTRODUCCIÓN}

Una de las líneas de investigación seguidas en los estudios de un grupo social es la prosopografía, es decir la biografía colectiva de los individuos que lo componen (Stone, 1986, p. 61). A través de la información biográfica obtenemos perfiles, trayectorias y pautas de comportamiento que permiten construir la identidad de un grupo social. Sin embargo, los estudios sobre redes sociales han puesto de manifiesto las limitaciones de este método para la caracterización de un grupo socio-profesional. Como advierte Imízcoz, los individuos que lo componen «no actúan en un campo único ni tienen una sola identidad», lo que exige tener en cuenta su propia diversidad interna y reconstruir el conjunto relacional en que se mueven (Imízcoz, 2009, p. 82). Para ello propone el análisis de los vínculos y redes sociales, un estudio realizado a través de las trayectorias y biografías de estos «actores sociales», de sus alianzas y amistades, que permita descubrir sus conexiones con otros grupos y construir su propia identidad social.

En el caso de los médicos, objeto de nuestra investigación, la definición de colectivo socio-profesional viene dada por su actividad, independientemente del marco o espacio en que ésta se realizara. El grupo no puede ser más abigarrado y heterogéneo. Junto a una minoría que alcanzó una mayor proyección científica y social por la relevancia de su cargo y el hecho de ser autores de obras impresas, ejercían en España centenares de médicos que desarrollaban su profesión en ciudades y pueblos del país, con trayectorias profesionales muy diversas y con papeles muy distintos en el entramado social de su tiempo. Sin embargo, el interés de los historiadores por las biografías individuales condujo a que estos individuos fueran completamente desconocidos e invisibles, situación que lentamente está cambiando con la recuperación de la colectividad como protagonista de la historia. Ya en 1974 Shapin y Thackray subrayaban la importancia de los estudios prosopográficos para la adecuada contextualización histórico-social de una colectividad de científicos, aunque entre los historiadores de la medicina españoles este tipo de investigaciones, más difíciles, lentas y laboriosas, cuentan con una escasa aceptación (Shapin y Thackray, 1974, p. 4). Debemos destacar los estudios de Pardo Tomás y Martínez Vidal sobre los médicos novatores en la corte española de finales del siglo XVII y principios del XVIII, línea que han proseguido con el análisis de los médicos que ejercieron en la corte de Carlos II y Felipe V (Pardo Tomás y Martínez Vidal, 2005, pp. 57-58). Sin embargo, aún sabemos muy poco acerca de la mentalidad de los médicos españoles, de sus trayectorias académicas y profesionales, valores familiares, intereses económicos, inquie- 
tudes intelectuales o de sus relaciones con los grupos de poder local. Pensamos que esta propuesta metodológica que conjuga la prosopografía con el análisis de las redes sociales (familia, amistades, clientela), prácticamente inexplorada como instrumento de análisis social de la profesión médica, puede aportar valiosos resultados.

A través de estudios anteriores pudimos constatar la heterogeneidad de este colectivo, diferencias que en ningún caso estuvieron determinadas por el espacio rural o urbano en que desarrollaron su actividad profesional, sino por el volumen de su riqueza, poder y grado de notoriedad pública (Granjel, 2009a, pp. 324-325 y Granjel, 2009b, pp. 11-12). Sólo una minoría de los médicos que ejercieron en Extremadura en el siglo XVIII alcanzó la condición de individuo preeminente, estatus que no sólo exigía reunir fortuna, prestigio, poder y respetabilidad social, requisitos definitorios de las élites según Eiras Roel, sino además notabilidad pública ${ }^{1}$. El análisis de los vínculos familiares, relaciones con la oligarquía y las redes sociales tejidas al hilo de sus trayectorias y actividad profesional, nos permitió profundizar en los mecanismos que hicieron posible el ascenso social de estos individuos. De otro lado, el estudio de sus valores familiares, intereses económicos, cuantía y diversidad del gasto privado, número de sirvientes o las disposiciones relativas a su funeral, permitieron la caracterización de una minoría de estos facultativos como miembros de las élites locales.

El deseo de profundizar en la identidad de este grupo social, nos ha llevado a estudiar el perfil, trayectoria, mentalidad y pautas de comportamiento de los médicos que ejercieron en Salamanca a lo largo del siglo XVIII ${ }^{2}$. Se trata de un grupo de facultativos que desarrollaron su actividad profesional en una ciudad que en 1787 contaba con una población de 16.267 habitantes y donde la Universidad desempeñó un papel fundamental en la vida de la ciudad. Todos ellos eran profesores de la Facultad de Medicina, circunstancia que introducía una diferencia importante con respecto a los médicos que sólo realizaron una actividad asistencial.

El método seguido en los estudios de este tipo es muy laborioso. Exige bucear en la enorme masa documental encerrada en los protocolos notariales, actas capitulares, libros parroquiales y documentación estrictamente académica. Unas fuentes que han sido ampliamente utilizadas en estudios sobre cultu-

1 Ha sido Pro Ruiz el primero en llamar la atención sobre este rasgo de las élites. Pro Ruiz, 1995, p. 49. Véase también Eiras Roel, 1984, p. 121.

2 El estudio se apoya en las biografías de 25 médicos y cubre todo el siglo XVIII, desde 1714 (fecha en que falleció José Colmenero) hasta 1806 (año de muerte de Francisco Otero). 
ra material, libros y bibliotecas, historia económica o sobre actitudes colectivas frente a la muerte. También en investigaciones sobre élites locales, trabajos que mayoritariamente se han centrado en los grupos que tuvieron una mayor proximidad con el poder, como la nobleza, oligarquías locales o miembros del gobierno y la Administración. Por el contrario, los estudios prosopográficos cuentan con muy escasa tradición entre los historiadores de la ciencia, situación que pensamos está determinada por las mayores dificultades para acceder a las fuentes documentales, más dispersas y menos abundantes que las de otros grupos sociales (Olagüe, 2005, pp. 145-146). Tampoco ha sido una línea seguida en las investigaciones sobre el profesorado universitario, situación que nos impide realizar análisis comparativos.

\section{PRIMEROS PASOS: LA CARRERA DE CÁTEDRAS}

Como en otras ciudades universitarias, la procedencia geográfica de estos facultativos fue muy diversa. Junto a una minoría que había nacido en Salamanca (Manuel Joly Orozo, José Parada Figueroa, Manuel Herrera Comán, Antonio Méndez, Francisco Gómez o Antonio Cuesta), la mayoría procedían de otras ciudades y regiones españolas (Extremadura, Cantabria, Toledo, Soria, Asturias, Orense, Girona, Zamora, etc.) y habían llegado a la ciudad en su etapa de estudiantes. La franja de edad con que iniciaban los estudios de Medicina osciló entre los 19 años que tenía Francisco Ovando y los 22 de Juan Francisco González Cernuda, edad en la que ya contaban con el preceptivo bachilleramiento en Artes. En ocasiones el estudiante iniciaba sus estudios médicos sin contar con este título, situación excepcional e irregular que requería la intervención del rector. En esta circunstancia se vio Pedro Ferrer, natural de Beguda (Girona), que «por ignorancia» había finalizado los estudios del primer curso de Medicina «sin el examen de Artes». El problema fue obviado por el Rector, que «mandó se le probase dicho primer curso, y sin que sirva de ejemplo, por ser sujeto muy estudioso, aprovechado y pobre» ${ }^{3}$. Los estudios de Artes se prolongaban durante tres años, que quedaron reducidos a dos tras la reforma universitaria de Carlos III.

Los estudios de Medicina tenían una duración de cuatro años, a lo largo de los cuales los estudiantes recibían lecciones de «Medicina teórica, Filosofía

3 La carrera académica de Pedro Ferrer fue corta. En 1748 fue nombrado catedrático de Partido Mayor y dos años más tarde pasaba a regentar la cátedra de Anatomía. En 1754 abandonaba la Universidad para ocupar la plaza de médico del Cabildo de la catedral de Segovia, puesto que le deparaba mayores ingresos. 
natural, Anatomía, Cirugía, Método y Práctica». Los textos empleados para la docencia eran los de Hipócrates, Galeno y Avicena, obras que los estudiantes debían adquirir en el segundo curso y que encontramos en todas las bibliotecas de médicos que hemos estudiado 4 . Con la aprobación del Plan de estudios de 1771, se ampliaron a ocho las cátedras de Medicina y se modificaron algunos de sus nombres: dos de Instituciones, dos de Aforismos, manteniéndose las de Pronósticos, Anatomía, Cirugía y Partido Mayor. La reforma supuso el abandono definitivo del galenismo arabizado y la apertura a la Medicina vigente en Europa (Carreras, 2006, p. 318 y Peset, 1969, pp. 38-40). Con la introducción de las obras de Boerhaave y sus comentaristas, la de Heister en las lecciones de Anatomía y la Cirugía de Porter, se consiguió la modernización de las enseñanzas impartidas. El resurgir del hipocratismo desde las primeras décadas del siglo XVIII, mantuvo la enseñanza de los Aforismos, Pronósticos y las Epidemias.

El coste de las matrículas, libros y de la estancia lejos del domicilio paterno durante el tiempo que duraban los estudios, proporciona ya un rasgo acerca de la procedencia familiar de estos médicos. Generalmente pertenecían a familias acomodadas, con aspiraciones, preocupadas por proporcionar un futuro con horizontes a sus hijos. Francisco Gómez procedía de una familia de propietarios de la localidad salmantina de Pitiegua, el padre de Juan Francisco González Cernuda era hidalgo, el de José Parada Figueroa era un cualificado funcionario de Salamanca, el de Manuel Herrera Comán escribano, el de Manuel Joly Orozco era catedrático en la Facultad de Medicina y el de Pedro Carrasco Zambrano militar. Todos ellos pudieron hacer frente a los gastos derivados de estos estudios, que en el caso de Francisco Ibáñez Neto del Castillo y de su hermano Antonio le habían supuesto a su padre, médico titular de Cáceres, un desembolso de 18.000 reales (Granjel, 2009a, p. 321). Una cantidad elevada que sólo podía satisfacer un pequeño sector de la población y que constituyó el principal obstáculo para acceder a una formación universitaria.

Estos gastos, con ser cuantiosos, se incrementaban notablemente cuando las ambiciones profesionales del médico le llevaban a seguir la carrera académica. Sin embargo, sólo una minoría de los cientos de estudiantes que cursaron sus estudios de Medicina en Salamanca a lo largo del siglo XVIII, formó parte del claustro de su Universidad. La mayoría abandonaba Salamanca

4 Para conseguir el título de bachiller en Medicina, los estudiantes debían probar «haber tenido desde su segundo año Libros Hipócrates, Galenos y Avicenas», requisito que desapareció tras la aprobación del Plan de Estudios de 1771. El estudio de las bibliotecas de estos médicos será objeto de un trabajo ulterior. 
al concluir sus estudios, buscando en otros lugares del país una plaza de médico en la que ejercer su profesión. Esta realidad nos lleva a profundizar en las trayectorias de los que permanecieron en la Universidad y en los mecanismos que hicieron posible su promoción.

Para seguir la carrera académica era necesario obtener los grados mayores, títulos que sólo alcanzaron una minoría de los bachilleres médicos 5 . En la Universidad de Salamanca debían transcurrir tres años entre la recepción del grado de bachiller (que era el que habilitaba para el ejercicio de la profesión médica) y el de licenciado. Durante este tiempo el candidato debía realizar lecturas extraordinarias de materias pertenecientes a las cátedras de regencia (las denominadas pasantías) y, además, tenía que llevar a cabo un ejercicio de 'repetición pública', acto de gran solemnidad en el que intervenían los doctores de la Facultad y tres bachilleres o licenciados nombrados por el rector. Cumplidos estos requisitos, el candidato realizaba el examen de grado en la capilla de Santa Bárbara ante los cuatro catedráticos examinadores de su Facultad y otros doctores y graduados. Por el contrario, para el grado de doctor no se exigían requisitos de índole académica y la colación se reducía a festejos y celebraciones que hicieron del acto una «pura ceremonia» (Peset, 1969, pp. 38-40).

Conviene subrayar el carácter minoritario y restrictivo de estos grados para entender el prestigio social y profesional de cuantos los conseguían. El reducido número de estudiantes que accedían a ellos no se debió a dificultades de índole académica o intelectual, sino a obstáculos fundamentalmente económicos. El ceremonial que se seguía en la Universidad de Salamanca para obtener la licenciatura exigía grandes dispendios, unos gastos que eran aún mayores para el grado de doctor.

El ejemplo de Francisco Ovando puede servirnos para valorar el desembolso económico que suponía «seguir la carrera de cátedras». Natural de la localidad pacense de Almendral, Ovando inició los estudios de Medicina en octubre de 1733 y alcanzó el grado de bachiller en 17376. Ese mismo año firmaba un contrato como médico titular de la villa de Madrigal (Ávila), aun-

5 El grado de licenciado era necesario para seguir la carrera universitaria, mientras que el de doctor, que tenían todos los catedráticos, era de carácter más honorífico. En el periodo comprendido entre 1700 y 1751 la Universidad de Salamanca formó a 312 bachilleres médicos, de los cuales sólo 30 alcanzaron el grado de licenciado y 20 el de doctor. Véase Rodríguez-San Pedro, Polo Rodríguez y Alejo Montes, 2004, pp. 653-658.

6 Ovando nació en 1714 y falleció en Salamanca en 1758, siendo catedrático de Pronósticos. Cuando ingresó en la Facultad de Medicina era un joven de 19 años, de «pelo castaño, ojos garzos y grandes, con una cicatriz en la ceja izquierda». Archivo Universitario de Salamanca (en adelante AUSA), lib. 555, f. 29v. 
que en los años siguientes volvería a Salamanca a realizar las lecturas y ejercicios necesarios para logar los grados mayores. Sin embargo, los 4.400 reales anuales que recibía de salario por su actividad como médico resultaban insuficientes para sufragar su elevado coste y en esa fecha su situación económica y patrimonial era precaria. El matrimonio que contrajo en 1741 con Paula de Soria, hija de una acomodada familia de Salamanca, le permitió contar con el apoyo económico necesario. Ovando invirtió los 11.000 reales que aportó su mujer en concepto de dote para sufragar una parte de estos gastos, suma que completó su suegro, Francisco de Soria, para que Ovando pudiera satisfacer los 6.444 reales de los gastos del «grado de Licenciado por la Capilla de Santa Bárbara» y los 10.543 reales del grado de Doctor. En estas cantidades se incluían el importe de los derechos o tasas, las propinas a examinadores y oficiales, los refrescos, comidas y colaciones con que se agasajaba a los doctores y maestros y los gastos de ropa del graduado (vestido de golillas, borla, muceta y botones) ${ }^{7}$. Un coste ciertamente elevado (16.987 reales en el caso de Francisco Ovando) que frenó las ambiciones académicas de muchos médicos. Para la mayoría de quienes los alcanzaron la inversión realizada fue altamente rentable, al proporcionarles influencia, prestigio y una red de relaciones de gran importancia en el proceso de ascenso social.

En ocasiones la muerte prematura del graduado dejaba a su familia en una situación económica muy precaria, especialmente si éste había tenido que solicitar un préstamo para hacer frente a los gastos de graduación. Lo comprobamos en el caso de Antonio Méndez, catedrático de Anatomía que falleció a los dos años de alcanzar los grados mayores. Las disposiciones testamentarias en relación a su funeral y entierro están muy alejadas de las que hacían los médicos que regentaban las cátedras de propiedad, ansiosos de exhibir su prestigio, posición y recursos económicos a través del fasto y el boato de su funeral. Por el contrario, las exequias de Méndez se limitaron a los «oficios acostumbrados» y se hicieron sin acompañamiento de cofradías, hechos que confirman su escasa proyección social y sus limitados recursos ${ }^{8}$. Las dificultades económicas obligaron a su viuda a solicitar la ayuda de la Universidad, al haber quedado «sumamente pobre a causa de los empeños que dicho su marido contrajo para recibir los grado de Licenciado y de Doctor

7 En el inventario de bienes practicado tras su muerte se recoge una minuciosa relación de todos estos gastos. Archivo Histórico Provincial de Salamanca (en adelante A.H.P. Salamanca). Protocolos, leg. 4198, ff. 720v-730v.

8 Antonio Méndez nació en Salamanca en 1713 y falleció en 1742 . Su testamento en A.H.P. Salamanca. Protocolos, leg. 5532, ff. 216r-217v. 
y seguir la carrera de la Universidad $\iota^{9}$. Este tipo de limosnas estaban contempladas en los Estatutos de la Universidad, aunque por su reducía cuantía se permitía que los interesados (viudas, huérfanos o profesores y oficiales jubilados) pudieran solicitarlas en más de una ocasión. En esa fecha «la limosna que prevenía el estatuto» era de 10.000 maravedíes (294 reales), cantidad que la viuda de Méndez recibió al menos en cinco ocasiones.

La trayectoria de los médicos que alcanzaban los grados mayores es muy similar a la de Francisco Ovando. Hasta que conseguían regentar una cátedra, se mantenían del ejercicio de su profesión en alguna localidad cercana. Manuel Herrero ejercía en la villa salmantina de Ledesma cuando en 1713 fue nombrado catedrático de Partido Mayor. Manuel Robles Quiñones fue médico titular de Gata, Alba de Tormes y Zamora hasta 1734, año en que fue nombrado catedrático de Anatomía. Esa misma cátedra era ocupada en 1739 por Manuel Herrera Comán, que ejercía en Zamora donde «tenía muchos enfermos». En 1748 se incorporaba a la cátedra de Partido Mayor Pedro Ferrer, que volvía a Salamanca tras varios años de ejercicio en la localidad vallisoletana de Peñafiel. En 1758 esta cátedra era ocupada por Antonio Cuesta, que regresaba a su ciudad natal tras ejercer varios años como médico titular en Piedrahita (Ávila) ${ }^{10}$. En 1760 esta misma cátedra era ocupada por Juan Martín, médico titular de Medina del Campo (Valladolid). Y en 1771 el nuevo catedrático de Partido Mayor fue Manuel Secades, médico hasta esa fecha en Alba de Tormes (Salamanca). Desde su incorporación como profesores a la Universidad, el proceso de ascenso académico sólo era cuestión de tiempo.

Al iniciarse el siglo XVIII existían dos tipos de cátedras en la Facultad de Medicina: las de propiedad (Prima, Vísperas y Pronósticos) y las denominadas cursatorias (Método, Simples, Anatomía y la de Partido Mayor). Mientras las primeras eran provistas por el Consejo Real previo informe de la Universidad sobre los méritos de los opositores, las cátedras cursatorias se cubrían mediante votación en los claustros plenos (Rodríguez-San Pedro y Polo Rodríguez, 2004, pp. 786-787). El sistema de provisión de las vacantes mediante ascenso de los catedráticos que regentaban las cátedras de menor categoría académica, pone de manifiesto el carácter endogámico de la Universidad y explica que la antigüedad y experiencia docente fueran los mecanismos habituales en la carrera universitaria.

9 AUSA, lib. 210, f. 39v

10 Como médico de esta localidad, que en el siglo XVIII pertenecía a la provincia de Salamanca, Cuesta percibía una asignación anual de 4.392 reales, a los que sumaba otros 1.000 reales «por las salidas que hace por apelaciones». Archivo General de Simancas (en adelante A.G.S). Dirección General de Rentas, $1^{a}$ Remesa. Respuestas Generales, lib. 499, f. 246 r. 
A través de la trayectoria del asturiano Juan Francisco González Cernuda podemos seguir la carrera académica de estos médicos ${ }^{11}$. En 1745 realizaba el examen de licenciado en la Capilla de Santa Bárbara y un año más tarde, el 2 de diciembre de 1746, alcanzaba el grado de doctor. En enero de 1747 fue nombrado catedrático de Partido Mayor, cátedra que había quedado vacante tras el ascenso a la de Anatomía de Francisco Ovando. En el mes de noviembre de ese mismo año solicitaba su promoción a la cátedra de Anatomía, que se hallaba vacante «por haber pasado a la de Simples el Dr. D. Juan Agustín de Medina», su anterior titular. González Cernuda ocupó este puesto docente hasta 1750, en que fue nombrado catedrático de Simples. En enero de 1760 accedía a la cátedra de Método y en junio de ese mismo año fue nombrado catedrático de Pronósticos. Sin embargo, la reiterada incomparecencia a las sesiones y actos literarios de la Universidad, conducta que algunos compañeros de claustro calificaron de «thema o manía» y otros de «mucha y refinada malicia», frenó su carrera académica y hasta 1779 no consiguió la promoción a la codiciada cátedra de Prima ${ }^{12}$.

\section{ESTRATEGIAS MATRIMONIALES Y REDES FAMILIARES}

La paulatina introducción en la España del siglo XVIII de una nueva escala de valores sociales, trajo consigo un proceso de cambio en el seno de la estructura estamental de la sociedad. El protagonismo económico y social que alcanzó la burguesía urbana (comerciantes, industriales, burócratas y profesionales liberales) permitió que algunos de estos individuos entraran a formar parte de las nuevas élites (Maruri, 1998, p. 748). El ascenso de este grupo (heterogéneo por su actividad y posición social y económica) se advierte no sólo en su presencia en los Ayuntamientos y en altos cargos de la Administración o en el ennoblecimiento y concesiones honoríficas otorgadas por Carlos III. Lo vemos también en la mayor permeabilidad social que se registra en la España del siglo XVIII. Como señala Casey, «entre los mercaderes y los es-

11 González Cernuda nació el 20 de diciembre de 1713 en la Ordovaga, pequeña localidad asturiana perteneciente al concejo de Navia. Cuando inició sus estudios de Medicina en 1736, era un joven de 22 años de «pelo castaño, ojos garzos, con una cicatriz en la nariz». AUSA. lib. 554, f. 51r.

12 Esta conducta dio lugar a dos reconvenciones (la primera en 1761 y la segunda en 1770 ) en las que se decidió recurrir a la sanción económica «pues es para él lo más sensible». AUSA, lib. 229, ff. 62r-62v y lib. 236, ff. 39v-40r, 56v-57r, 166r-168r y 200r-204r. 
cribanos, entre los tejedores de seda y los regidores, hay una escalera, estrecha sin duda, por donde suben y bajan los vecinos de la ciudad en la época moderna» (Casey, 2009, p. 56). Muestra inequívoca de la movilidad social a que se refiere este autor son las alianzas matrimoniales, instrumento utilizado por comerciantes, profesionales y burócratas en los procesos de ascenso social.

Veamos la conducta seguida por los catedráticos de Medicina de Salamanca a este respecto. Sus matrimonios con hijas de la oligarquía local, de mercaderes y artesanos acaudalados o de funcionarios y miembros de la Administración, perseguían unos fines claros y bien definidos. Objetivos que iban desde su promoción académica (como en el caso de Francisco Ovando), hasta el deseo de incrementar su fortuna o el establecimiento de nuevas relaciones y alianzas de poder. En un trabajo anterior pudimos constatar la importancia que tenía el contar con una formación universitaria a la hora de realizar un matrimonio ventajoso (Granjel, 2009a, pp. 323-324). Aunque el ejemplo de Francisco Ovando parece confirmar este hecho, las biografías de otros médicos no se ajustan a este patrón e introducen un conjunto de elementos que obligan a un seguimiento de sus trayectorias individuales.

La tradición universitaria de Salamanca y el menor prestigio de su Facultad de Medicina frente a las jurídicas, influyó decisivamente en las pautas de comportamiento de las familias salmantinas en las elecciones matrimoniales para sus hijas. Junto a los miembros de la pequeña nobleza, las élites de la ciudad estaban integradas por la burguesía acaudalada, abogados, funcionarios reales, administradores de rentas y algunos miembros del claustro de su Universidad (Cabo, 1992, pp. 64-65). La consideración social que alcanzaron los abogados y letrados y la menor proyección universitaria de las cátedras de Medicina, peor remuneradas que las jurídicas, permite entender las dificultades de muchos médicos para lograr el poder, ascendencia y prestigio que tenían los hombres de leyes. Un fenómeno que también se produjo en Francia, donde el nivel de cualificación exigido a los funcionaros del Estado determinó el auge de los estudios jurídicos y la mayor consideración de estos profesionales (Grecenková, 2004, pp. 505-506).

En este contexto es preciso valorar las dificultades de algunos médicos recién graduados para establecer alianzas familiares con los grupos de poder local, especialmente si carecían de un patrimonio familiar que asegurase el estatus social de su futura esposa. Lo comprobamos en el caso de José Colmenero, casado en primeras nupcias con Isabel Conde de Recalde y que falleció sin testar «por hallarse muy pobre de calidad» ${ }^{13}$. O en el de Manuela de

13 Colmenero se incorporó a la Facultad de Medicina en 1766 y recorrió todas las cátedras hasta su jubilación en 1708, siendo catedrático de Prima. Falleció en Salamanca en 1714 
Cueñas, primera mujer de González Cernuda, que por idénticos motivos tampoco otorgó testamento. También lo vimos en el matrimonio de Antonio Méndez, cuya mujer sólo llevó «diferentes alhajas de por casa, ropa de lino y lana, cama y otras cosas» por importe de 1.500 reales. Si tenemos en cuenta que el importe medio de las dotes estudiadas ascendió a 21.323 reales, se constata la procedencia social más modesta de la mujer de este facultativo ${ }^{14}$. Aunque no fueron situaciones habituales, debemos dejar constancia de ellas.

Sólo cuando el médico contaba ya con una carrera académica y profesional consolidada, las reticencias hacia estos enlaces eran menores. Lo observamos en los casos de segundas y terceras nupcias, en los que la futura esposa tenía ya garantizado un estatus social más relevante. Los sucesivos matrimonios del catedrático José Colmenero son un buen ejemplo de estas situaciones. En 1682 , tras la muerte de su primera mujer, contrajo segundas nupcias con Dorotea de Acebedo, que aportó una dote de 4.400 reales. Cuando ésta falleció, Colmenero ya regentaba la cátedra de Vísperas y disfrutaba de una posición destacada, circunstancias que le permitieron realizar un matrimonio altamente rentable. Los 53.000 reales que aportó Catalina Rodríguez de la Torre a este enlace, realizado en 1709, muestra la acaudalada situación de su familia. La posición social y económica que alcanzó Colmenero con esta unión, le permitió acrecentar sus relaciones y adquirir «muchos bienes gananciales», que incrementaron notablemente su patrimonio. La designación del regidor Pedro Tamayo y Téllez como albacea testamentario de su tercera mujer, revela de qué modo este matrimonio contribuyó a la integración de Colmenero en el círculo social de las élites ${ }^{15}$.

Otro ejemplo de estas situaciones lo tenemos en Juan Francisco González Cernuda, que en 1753 contraía segundas nupcias con Ana Mª Hernández Ayllón, hija de un acaudalado platero de la ciudad. Para este facultativo, que en esa fecha regentaba la cátedra de Simples, el matrimonio constituyó una clara estrategia para mejorar su posición económica, elemento decisivo en los pro-

y fue autor de un obra (Reprobación del pernicioso abuso de los polvos de la corteza del quarango o China china, ... en cuanto especial febrifugo, Salamanca, 1697) que originó una viva polémica.

14 En la documentación estudiada hemos encontrado información relativa a las dotes aportadas por las mujeres de 15 profesores de Medicina. La horquilla de estos bienes es amplia y osciló entre los 53.000 reales que aportó Catalina Rodríguez de la Torre a su matrimonio con José Colmenero y los 1.500 reales de Bárbara Fernández, esposa del citado Antonio Méndez.

15 En el testamento de Colmenero otorgado en 1713, un año antes de morir, se comprueba el papel de su matrimonio con Catalina Rodríguez de la Torre en el proceso de ascenso social. A.H.P. Salamanca. Protocolos, leg. 3807, ff. 263r-272v. 
cesos de ascenso social. La dote de 30.000 reales que aportó la mujer a este matrimonio, le permitió disfrutar de una situación económica que difícilmente habría alcanzado con su actividad docente y asistencial. Por su parte, para la familia Hernández Ayllón el objetivo de este enlace no era otro que reforzar sus vínculos con el estamento universitario, gremio al que pertenecían dos de los hijos del matrimonio ${ }^{16}$. Una trayectoria similar siguió Blas Pérez de Villarta, que en 1729 contraía segundas nupcias con Beatriz Cornejo de Paz hija de un regidor y miembro de uno de los linajes más antiguos de la ciudad ${ }^{17}$. Su matrimonio, como los de Colmenero o González Cernuda, confirma la importancia de estas alianzas a la hora de acrecentar relaciones e influencias, de abrir redes hacia nuevas esferas y, también, de su papel en el proceso de enriquecimiento y ascenso social de un facultativo.

La situación era muy distinta cuando los médicos contaban con un patrimonio familiar que les permitiera contribuir con sus propios bienes a la sociedad conyugal. La conexión entre estatus social y relaciones era muy estrecha, lo que explica las alianzas entre individuos con una misma posición y un nivel semejante de fortuna y poder. Cuando contrajo matrimonio con $\mathrm{M}^{\mathrm{a}} \mathrm{An}$ tonia Foncueba, José Parada Figueroa aportó «por caudal mío propio 24.000 reales en especie de dinero, plata, oro, diamantes, vestidos, librería y otras cosas $\rangle^{18}$. Cantidad elevada para un médico recién graduado, aunque inferior a los 38.000 reales que importaron el conjunto de bienes aportados por su mujer. Ambos pertenecían a familias de funcionarios y letrados, lo que hace de esta unión un ejemplo de matrimonio entre iguales. Un tipo de alianzas realizadas con el objetivo de intentar mantener el sistema de jerarquización social establecido y reproducir el estatus social y económico de ambas familias.

En la sociedad del Antiguo Régimen la endogamia jugó un papel muy importante como mecanismo de reproducción social. Contribuía a reforzar grupos de parentesco entre familias con intereses comunes, esencial en la cohesión y consolidación no sólo de la oligarquía, sino también del resto de grupos

16 José Hernández Ayllón era catedrático de Retórica, mientras que su hermano Francisco era el titular de la cátedra de Código.

17 Natural de la villa de Membrilla (Ciudad Real), Pérez de Villarta fue catedrático de la Facultad de Medicina desde 1709 hasta su muerte en 1738, fecha en que ocupaba la cátedra de Pronósticos.

18 El salmantino José Parada tuvo una dilatada vida académica; se incorporó al claustro de profesores de la Facultad de Medicina en 1709 como catedrático de Partido Mayor y se jubiló en 1746, fecha en que ya ocupaba la codiciada cátedra de Prima. En 1759 otorgó un testamento conjunto con su mujer que proporciona abundante información personal. Parada falleció en Salamanca en 1765. 
sociales (Imízcoz, 1996, p. 34). Junto al deseo de evitar la disgregación del patrimonio familiar, especialmente entre los sectores más acomodados, estas alianzas contribuyeron a crear auténticas sagas en la Administración, la magistratura y en otros servicios a la monarquía. A través del estudio de capitulaciones matrimoniales, Eiras Roel ha detectado una fuerte endogamia entre los miembros «del mundo del negocio y de la toga» de la ciudad de Santiago de Compostela, conducta que no advierte en el seno del estamento universitario (Eiras Roel, 1981, p. 64). Por el contrario, en Salamanca fueron frecuentes los matrimonios entre los miembros de la Universidad, alianzas realizadas con el objetivo de reforzar los vínculos académicos de estas familias y favorecer la progresión universitaria de sus hijos. Sin olvidar que a través de la extensión de la consanguinidad en el seno del claustro salmantino, estas familias alcanzaban un mayor control de la institución.

Un ejemplo muy ilustrativo de estas situaciones lo encontramos en los Joly, una familia de ascendencia hidalga originaria del Franco Condado ${ }^{19}$. A mediados del Seiscientos llegaba a Salamanca Gabriel Joly, que tras concluir sus estudios decidió proseguir la carrera académica, regentando durante más de tres décadas la cátedra de Cirugía. Su hijo Gabriel Joly Daloz siguió la trayectoria de su padre y tras doctorarse en Medicina en 1683, desempeñó las cátedras de Simples, Método y Pronósticos ${ }^{20}$. La familia que formó tras su matrimonio con una hija de Bernardo de Orozco, catedrático en la misma Facultad, reforzó los vínculos universitarios de los Joly, unos lazos que afianzaron sus tres hijos. Estefanía Joly Orozco estaba casada con Pedro Carrasco Zambrano, que se incorporó a la Facultad de Medicina en 1692 como catedrático de Partido Mayor ${ }^{21}$. Por su parte su hijo Gabriel, que siguió la carrera de Leyes, contrajo matrimonio con una hija de Francisco de Espinosa Guzmán, catedrático de Prima de la Facultad de Medicina. El tercero de los hijos, Manuel Joly Orozco, siguió la trayectoria profesional de su padre y tras concluir sus estudios médicos inició la carrera académica, llegando a ocupar la cátedra de Prima ${ }^{22}$. La tradición universitaria de la familia la

19 La información de nobleza de la familia Joly en Archivo de la Real Chancillería de Valladolid (en adelante ARCHV). Sala de Hijosdalgo. Caja 1130.0024.

20 Fue autor de una obra titulada Disputatio de morbo gallico (1677) que no llegó a publicarse. Véase Lilao y Castrillo, 1997, p. 208.

21 Natural de Llerena (Badajoz), Pedro Carrasco procedía de una familia de militares originaria de dicha localidad. Falleció en 1737 siendo catedrático jubilado de Prima. Su testamento en A.H.P. Salamanca. Protocolos, leg. 3945, ff. 318r-319v.

22 Casado con Clara de la Cruz y Castro, hija de una acaudalada familia salmantina, Manuel Joly Orozco entró a formar parte del claustro universitario de Salamanca en 1695. En 1704, siendo catedrático de Simples, abandonó la ciudad para ocupar la plaza de médico de la 
mantuvo su primogénito Miguel Joly de la Cruz, catedrático en la Facultad de Derecho.

Esta familia no fue una excepción; a poco de graduarse Francisco Vélez de Cabiedes contraía matrimonio con Josefa Herrero Gómez, hija del catedrático de Simples Manuel Herrero. A la muerte de su mujer, que falleció sin descendencia en 1750, Vélez heredó todos sus bienes ${ }^{23}$. No es necesario incidir mucho más en la importancia que tuvieron estos enlaces como mecanismos de promoción académica y profesional de estos facultativos, así como en la construcción de redes de parentesco en el seno de la comunidad universitaria.

Un caso especial de endogamia matrimonial es el de los Rodríguez Tejerina, una acaudalada familia de ascendencia hidalga originaria de la villa de Cisneros (Palencia). José Rodríguez Tejerina, que disfrutaba «el asiento de municiones y otras distintas dependencias», se había casado con la salmantina Jacinta González de Rueda, asimismo de condición hidalga. Su hermano Francisco, por su parte, contrajo matrimonio con Teresa Flores, hija de un regidor de la ciudad. En ambos casos se trataba de enlaces muy ventajosos que reforzaron la situación patrimonial y el ámbito de relaciones de los dos hermanos. Serán sus descendientes quienes establezcan los vínculos con miembros del claustro universitario. La única hija de José contrajo matrimonio con Jacinto de la Peña, catedrático de Leyes, mientras que la hija de Francisco lo hacía con Pedro Riaguas, que en esa fecha ocupaba la cátedra de Partido Mayor. Unas alianzas que resultaron altamente ventajosas para ambos profesores, al convertirles en unos individuos acaudalados y muy bien posicionados socialmente.

La trayectoria de Pedro Riaguas revela la importancia de este enlace en su proceso de ascenso social24. Cuando se casó su capital se reducía a los 1.000 reales que «con corta diferencia» aportó a la sociedad conyugal, una cantidad muy alejada de los 41.000 reales que llevó su mujer en concepto de dote. Es-

ciudad de León. Se reincorporó a la Universidad en 1720 como catedrático de Pronósticos, al año siguiente pasó a ocupar la de Vísperas y desde 1733 hasta su muerte en 1738 desempeñó la cátedra de Prima. Su testamento en A.H.P. Salamanca, Protocolos, leg. 5347, ff. 425r-428r.

23 Francisco Vélez de Cabiedes nació en 1714 en la localidad cántabra de Sierra de Ibio. En 1740 alcanzó los grados mayores y al año siguiente se incorporaba a la Facultad de Medicina como catedrático de Partido Mayor. Tras la muerte de Josefa Herrero contrajo segundas nupcias con Manuela de España, miembro de una familia de boticarios salmantinos y madre de su única hija. Vélez falleció en 1781, siendo catedrático jubilado de Prima. Su testamento en A.H.P. Salamanca, Protocolos, leg. 4828, ff. 948r-951r.

24 Natural de la ciudad de Soria, Pedro Riaguas se incorporó a la Facultad de Medicina en 1734 y falleció en 1746 siendo catedrático de Método. Su testamento e inventario de bienes en A.H.P. Salamanca, Protocolos, leg. 5186, ff. 507r-509v y 537r-569v. 
tos bienes, junto a los recibidos tras la muerte de su suegro Francisco Rodríguez Tejerina, le permitieron disfrutar de una posición económica privilegiada para un catedrático de Medicina. Pero además, los vínculos creados a partir de este enlace fueron de gran valor para generar nuevas relaciones y ampliar su red de pacientes. Su elevado nivel de renta le permitió invertir parte del dinero acumulado en operaciones de crédito a miembros de la oligarquía ciudadana, que aquejados por problemas de dinero estaban atrapados en esta red de préstamos. En el inventario de bienes practicado tras su muerte se recoge una minuciosa relación de sus deudores y de la cuantía de estos préstamos, que ascendía a más de 40.000 reales $^{25}$. Una suma importante que, unida al resto de bienes que dejaba, atestigua su saneada posición económica.

Pero volvamos a la otra rama de esta familia. La muerte prematura de Josefa Rodríguez Tejerina dejó a Jacinto de la Peña viudo y con una hija de corta edad. Los intereses familiares propiciaron sus segundas nupcias con Estefanía de Huerta Rodríguez Tejerina, sobrina carnal de su primera mujer. Este enlace no impidió que su suegro instituyera un vínculo con todos sus bienes a favor de su nieta, Francisca de la Peña Rodríguez Tejerina. El conjunto de propiedades vinculadas a esta fundación era cuantioso: diez casas en la ciudad que deparaban cerca de 3.000 reales anuales de renta, diferentes fincas rústicas que formaban parte de la hacienda familiar en la provincia y tres censos, uno de ellos de 34.000 reales de principal y 1.020 de sus réditos anuales «contra los Señores Concejo y Regimiento de esta ciudad» ${ }^{26}$. El matrimonio de Francisca de la Peña Rodríguez Tejerina con el catedrático de Medicina Antonio Ballesteros, reforzó las relaciones de esta familia con el estamento universitario. Gracias a esta unión Ballesteros se convirtió en uno de los facultativos más acaudalados de Salamanca, no sólo por la dote que aportó su mujer (44.000 reales), sino por el abultado patrimonio que heredó tras la muerte de su abuelo ${ }^{27}$. Este matrimonio permitió que Ballesteros alcanzara una posición social destacada y corrobora el papel de estos enlaces en la configuración de las élites.

25 La tipología de los individuos que solicitaban estos préstamos es muy heterogénea y su cuantía osciló entre los 6.100 reales que prestó a José Narciso Álvarez (regidor perpetuo de Salamanca) y los 114 reales que entregó a Juan Antonio de Rivas, colegial en el Pan y Carbón. Cuando las cantidades solicitadas eran elevadas, las familias entregaban a Riaguas diferentes objetos de oro y plata como garantía de estos préstamos.

26 En el testamento de José Rodríguez Tejerina se recogen todas las propiedades y bienes del vínculo. A.H.P. Salamanca, Protocolos, leg. 3436, ff. 430r-445r.

27 El inventario de bienes practicado tras la muerte de Ballesteros, que falleció en 1784 siendo catedrático de Partido Mayor, permite constatar la acaudalada posición de su mujer. A.H.P. Salamanca, Protocolos, leg. 5222, ff. 1169r-1235v. 
El seguimiento de las alianzas matrimoniales de los hijos de estos médicos, muestra de qué modo contribuyeron a crear auténticas sagas en el seno de la comunidad universitaria. Los casos de las familias Joly y Rodríguez Tejerina no constituyeron una excepción. El matrimonio de Isabel Jiménez Lebrato (hija del catedrático de Vísperas de Medicina Manuel Jiménez) con Manuel de la Cruz García, catedrático de la Facultad de Cánones, o el de Josefa Sendín Ulloa (hija del catedrático de Cirugía Tomás Sendín) con Marcos Martín Oviedo, catedrático de la Facultad de Leyes, son otros ejemplos de la endogamia que comentamos. Si tenemos en cuenta que los vínculos familiares se extendían a los parientes de ambos cónyuges, las redes creadas en el seno de Universidad a través de estas uniones eran aún más amplias.

En otros casos las alianzas matrimoniales formaron parte de una estrategia más ambiciosa, dirigida a incrementar el capital de relaciones sociales fuera del gremio universitario. Los más afortunados lograron emparentar con la nobleza local, como la hija mayor de Pedro San Martín, casada con Manuel de los Arcos y Encina ${ }^{28}$. Otros concertaron matrimonios para sus hijas con miembros de la Administración que controlaban cargos públicos. Fue el caso de la hija mayor de Manuel Herrera Comán, que en 1753 contrajo matrimonio con Francisco Villarreal y Simancas, un abogado de los Reales Consejos que inició su carrera en la Administración como Alcalde Mayor de la villa de Bodonal y que en 1760 era Corregidor de Tordesillas ${ }^{29}$. O el de la única hija de Francisco Vélez de Cabiedes, casada con José Ramón Vélez Cosío, regidor en el Ayuntamiento de Salamanca. Estas alianzas revelan el estatus social alcanzado por estos médicos y su condición de individuos preeminentes. $\mathrm{Su}$ notoriedad y ascendencia social, el poder y prestigio que alcanzaron y su mayor nivel de ingresos (como se advierte en la cuantía de las dotes que dieron a sus hijas), les permitió formar parte de las élites locales y concertar unos enlaces altamente ventajosos para sus hijas. Unas alianzas que confirman la estrecha relación que había entre «condición social» y «redes de relaciones», reforzadas a partir de estos lazos.

28 Pedro San Martín fue catedrático de la Facultad de Medicina desde 1699 hasta su jubilación en 1733, siendo ya catedrático de Prima. Casado en segundas nupcias con María Mansilla, madre de sus tres hijos, San Martín falleció en Salamanca en 1743. Su testamento e inventario de bienes en A.H.P. Salamanca, Protocolos, leg. 4040, ff. 448r-496r.

29 El documento de capitulaciones matrimoniales se firmó en 1753, fecha en que Herrera Comán ya era catedrático de Prima. A.H.P. Salamanca, Protocolos, leg. 4918, ff. 649r-652v. 


\section{AMIGOS Y PACIENTES: LAS REDES SOCIALES}

Las redes tejidas al hilo de estos matrimonios se prolongaban fuera del círculo familiar mediante lazos de amistad con otros individuos, relaciones de confianza y reciprocidad desarrolladas, sobre todo, entre los miembros de un mismo círculo social o profesional. Para el estudio de estas redes se han utilizado fuentes muy diversas, desde registros parroquiales y documentación notarial, hasta diarios, memorias o correspondencia epistolar (Imízcoz, 2009, pp. 102-104). Nuestro planteamiento para profundizar en los vínculos sociales de los catedráticos de Medicina es doble: de un lado estudiaremos la tipología de sus albaceas testamentarios y, de otro, la extracción social de sus pacientes. Mientras en el primer caso las fuentes manejadas han sido ampliamente utilizadas, el estudio de los pacientes es más complejo y explica que sea una línea de investigación prácticamente inexplorada.

En derecho, el albaceazgo es un cargo de confianza que se deposita en personas designadas por el testador para que cuiden la ejecución de lo contenido en su testamento y, generalmente, era más de una persona la que mancomunadamente ejercía esta función (Gómez Navarro, 2000, p. 177). Al tratarse de un cargo de confianza, en la seguridad respecto al cumplimiento de las mandas y obligaciones contenidas en el testamento, la elección se basaba en la existencia de vínculos familiares, de amistad o profesionales con los testamentarios, lo que hace de esta documentación una fuente de gran valor para el análisis de estas redes.

La mentalidad de los catedráticos de Medicina a la hora de la muerte no difiere de la observada en otros sectores de la población española. Junto a una mayor confianza en los albaceas, en cuyas manos los otorgantes delegaban más funciones, comprobamos un mayor protagonismo de la familia, que a lo largo del siglo XVIII asumió responsabilidades que tradicionalmente eran encomendadas a personas ajenas al círculo más íntimo del moribundo (Ariès, 2000, pp. 181-182). En el caso de Pedro Carrasco, Francisco Ovando o de Manuel Joly Orozco, esta confianza determinó que todos sus testamentarios pertenecieran al entorno familiar.

El cambio de mentalidad que se registra en la España del siglo XVIII no sólo se advierte en esta seguridad en las esposas, hijos o parientes más cercanos, sino también en una menor presencia de eclesiásticos entre los albaceas. Esta incipiente secularización de los testamentos se observa en las disposiciones de Pedro Carrasco, Manuel Joly y Pedro Riaguas, que al designar a sus testamentarios prescindieron de los miembros del clero. Sin embargo esta conducta no fue la habitual y en el resto de los testamentos encontramos al 
menos un eclesiástico que garantizaba el cumplimiento de las voluntades piadosas del testador.

A diferencia de otros grupos sociales, los miembros del clero constituían un colectivo más heterogéneo. Junto a una mayoría que vivía de la congrua de las parroquias, hubo otros que alcanzaron una posición destacada por su alto nivel de ingresos y por los cargos y prebendas que disfrutaron. En la ciudad de Salamanca este sector, más elitista y privilegiado, estaba integrado por los miembros del cabildo catedralicio, de la Real Clerecía de San Marcos y los eclesiásticos que desempeñaban cátedras en la Universidad o dirigían algunos de sus colegios. La presencia de estos individuos entre los albaceas de los catedráticos de Medicina, permite descubrir la existencia de estos lazos y vínculos que unían a los poderosos. Francisco Ovando, Manuel Jiménez, Francisco Vélez de Cabiedes y Manuel Herrera Comán se distinguieron por su amistad con algún canónigo, mientras que José Colmenero, Juan Francisco González Cernuda, Francisco Otero y Antonio Cuesta mantuvieron estrecha relación con eclesiásticos vinculados a la Universidad, a quienes confiaron el cumplimiento de sus últimas disposiciones ${ }^{30}$.

Los lazos de amistad de algunos médicos con otros miembros de las élites de la ciudad se advierte en la inclusión de nobles, regidores y altos cargos de la Administración entre sus albaceas. José Colmenero (que gracias a su tercer matrimonio logró una posición preeminente) depositaba esta confianza en el regidor Juan de Barrientos y Solís; Manuel Herrera Comán lo hacía en José Pérez del Barco, miembro de la pequeña nobleza salmantina. Y las redes creadas por Antonio Ballesteros tras su matrimonio con Francisca de la Peña Rodríguez Tejerina le permitieron disfrutar de la amistad de Manuel de Pineda Pernia y Monroy, miembro asimismo de la oligarquía local y uno de sus testamentarios.

Las relaciones establecidas en el seno de la comunidad universitaria y el fuerte corporativismo de la institución, se advierte en la presencia de catedráticos como albaceas de sus compañeros de claustro. En el caso de Antonio Méndez, Francisco Gómez o Tomás Sendín la elección recayó en compañeros de su propia Facultad, mientras que Manuel Jiménez, José Colmenero, Pedro Riaguas, Juan Francisco González Cernuda o Antonio Ballesteros depositaron su confianza en catedráticos de otras facultades. Debemos advertir que sólo Jacinto de la Peña (albacea de Pedro Riaguas) pertenecía a la facultad de Leyes, aunque su designación pudo deberse a los vínculos familiares que les

30 En el caso de Francisco Ovando los vínculos familiares con el canónigo Blas García de Coca, hermano de su segunda mujer y uno de sus testamentarios, pone de relieve la fuerza de ese nuevo sentimiento hacia «los suyos» de cara a la muerte. 
unían $^{31}$. La reducida presencia de hombres de leyes entre los albaceas de estos médicos constituye un hecho significativo, sobre todo si tenemos en cuenta la función del testamento como instrumento jurídico. Sólo cuando existió una relación familiar, se incrementa la presencia de figuras relacionadas de algún modo con el mundo de la ley. Lo comprobamos no sólo en el caso de Pedro Riaguas, sino también en el de Francisco Vélez de Cabiedes (que designaba a su yerno José Ramón Vélez Cosío, abogado de los Reales Consejos) y en el de Tomás Sendín, que hacía lo mismo con su yerno Marcos Martín Oviedo, catedrático de la Facultad de Leyes.

Las relaciones generadas a través de estos mecanismos fueron de gran valor para los médicos. El carácter dominante de una medicina doméstica, domiciliaria, permite entender la importancia de los vínculos sociales a la hora de dominar el mercado terapéutico, un mercado complejo propio de una economía mercantil $^{32}$. Este modelo asistencial requería conseguir una clientela lo más extensa e influyente posible, para lo cual los médicos utilizaban todos los resortes de que disponían: el prestigio de la cátedra que regentaban, su experiencia profesional, los vínculos familiares o sus propias relaciones sociales. Ahora bien, para mantener su poder y destacada posición en el mercado sanitario de la ciudad era asimismo importante conservar esta clientela, fidelizarla. Una tarea no siempre fácil que exigía generar conexiones con diversos ámbitos y grupos sociales, cuanto más amplias, sólidas y diversificadas mejor ${ }^{33}$.

Por este motivo, los que iniciaban su carrera profesional en Salamanca se encontraban con la dura competencia de quienes llevaban más años de ejercicio y ocupaban cátedras de mayor prestigio y proyección social. Estos últimos eran los que acaparaban la asistencia de las élites y de los colegios e instituciones más importantes de la ciudad y, por ello, los que obtenían mayores ingresos por el ejercicio de su actividad. Por el contrario, los que iniciaban su vida profesional estaban obligados a mantenerse de las rentas de las cátedras cursatorias que disfrutaban y de la asistencia a los sectores más menesterosos de la población. Una situación que condujo a que algunos catedráticos aban-

31 La mujer de Pedro Riaguas (Josefa Rodríguez Tejerina) y la de Jacinto de la Peña (Josefa Agustina Rodríguez Tejerina) eran primas carnales.

32 El término 'mercado sanitario', de amplia aceptación, fue acuñado por la literatura anglosajona para referirse al marco social y cultural en que los médicos desarrollaban su actividad. Cook, 1986, pp. 19-22.

33 Sobre este tipo de relaciones véase Imízcoz, 1996, pp. 39-40 y Martínez Millán, 1992, pp. 21-22. 
donasen la carrera académica y aprovecharan el prestigio que conferían los grados mayores para lograr un puesto asistencial mejor remunerado ${ }^{34}$.

Veamos algunos casos que ejemplifican las diferencias económicas que comentamos. Cuando se practicaron las averiguaciones para el Catastro de Ensenada, a Juan Martín (médico recién graduado que llegaría a ser catedrático de Prima) le calculaban unas ganancias anuales de 300 reales, advirtiéndose que sólo le consideraban de utilidad «lo que le puede producir la borla» ${ }^{35}$. En esas mismas fechas los ingresos más elevados (12.000 reales anuales) los tenía José Parada Figueroa, catedrático jubilado de Prima. En otras ciudades españolas que contaban también con varios facultativos, la situación era muy similar. En Santiago de Compostela ejercía en esos años Plácido del Villar, médico del Cabildo, que disfrutó de un alto nivel de renta (12.000 reales); por el contrario para su compañero Manuel Martín, «médico suelto», el ejercicio de la Medicina no resultaba una actividad lucrativa. Los 1.000 reales de ingresos le situaban en el seno de lo que Eiras Roel define como «una baja clase media», situación que pone de relieve los contrastes existentes en el seno de este colectivo (Eiras Roel, 1984, p. 121). Fuera de España estas diferencias fueron asimismo habituales y junto a los médicos que apenas podían mantenerse con los honorarios que percibían, hubo otros que alcanzaron un alto nivel de ingresos, llegando a amasar grandes fortunas (Ramsey, 1988, pp. 55-56).

En una ciudad como Salamanca, que hasta principios del siglo XIX careció de facultativos titulares, los médicos se mantenían del ejercicio libre de su profesión, generalmente a través de las igualas que hacían con la población o con alguno de los hospitales, colegios y comunidades religiosas de la ciudad. Las familias que no tenían concertado este tipo de ajustes, recurrían a uno de los médicos de la ciudad cuando precisaban sus servicios. Ahora bien, mientras en muchos lugares de Europa la elección de un determinado facultativo no siempre se hacía por razones de adhesión social o por la mayor o menor confianza en su formación y experiencia, la situación detectada en Salamanca es distinta (Rieder, 2005, p. 46 y Pomata, 1998, p. 121). En esta ciudad el prestigio de su Universidad marcó las pautas de su población a la hora de consultar a un determinado médico $\mathrm{y}$, como veremos, los que regentaban las cátedras de propiedad y gozaban de una posición preeminente monopolizaron la asistencia de los sectores más acomodados.

34 El caso ya comentado de Pedro Ferrer o el de Manuel Robles Quiñones, que en 1745 se trasladó a Madrid como médico del duque de Medinaceli, son algunos ejemplos.

35 A.H.P. Salamanca. Catastro de Ensenada. Libro de Relaciones de Seglares, leg. 2057, f. $401 r$. 
Las fuentes para el estudio de este mercado son aún más dispersas. Junto a la información recogida en las denominadas respuestas particulares del Catastro de Ensenada, quizás la más rica para esas fechas, hemos utilizado la que deparan los inventarios post mortem, una documentación abultada y difícil de rastrear. Unas y otras permiten profundizar en las modalidades de ejercicio profesional, en los honorarios que percibía un facultativo por las igualas y consultas médicas, en la forma en que se satisfacían estas prestaciones y en la importancia de las redes sociales en el perfil y extracción social de sus pacientes.

La información que proporciona el inventario practicado tras la muerte de Pedro Riaguas, ofrece una interesante perspectiva del marco en que se desarrolló la práctica médica en Salamanca. Su viuda advertía a las autoridades «que el dicho Don Pedro asistía a varias casas de particulares y comunidades a la curativa de sus enfermedades, y en las unas estaba asalariado por trigo y cebada y en otras por maravedís. E igualmente en otras no había cosa fija porque quedaba al arbitrio de las partes la gratificación o remuneración del trabajo en la asistencia» ${ }^{36}$. Riaguas, como el resto de los médicos, tenía ajustes o igualas con diferentes sectores de la población y, además, prestaba asistencia puntual a los vecinos que solicitaban sus servicios.

¿A cuánto ascendía la minuta de un médico por las visitas domiciliarias que realizaba? En su vista a Valencia, Townsend refiere que «hoy día los honorarios de un médico están en dos peniques [2,56 reales] si el paciente es comerciante y diez [12,8 reales] si se trata de una persona acomodada» (Townsend, 1988, p. 407). Estas cantidades correspondían a la minuta por consulta médica, por lo que cuando la enfermedad se prolongaba la cuantía de estas prestaciones era mayor. Veamos algunos ejemplos. En 1748 Francisco Álvarez Landero, médico de la ciudad de Mérida, recibió 30 reales por la asistencia de Gabriel Bustamante, Administrador de la Renta de Salinas de esta ciudad. Idéntica suma percibió un facultativo salmantino (cuyo nombre no aparece recogido) por la asistencia de Antonio Pérez, «tratante de la Ribera», que murió en 1753 a consecuencia de su enfermedad. En ambos casos se trataba de una cantidad muy inferior a la que cobró Manuel Jiménez, catedrático de Vísperas de Medicina de Salamanca, por las visitas que realizó a Francisca de Espinosa, viuda de un escribano de la ciudad que falleció en $1742^{37}$. Aunque las fuentes nada dicen sobre el número de visitas realizadas por estos facultativos, cabe pensar que el prestigio de Manuel Jiménez influyó en la mayor cuantía de su minuta.

36 A.H.P. Salamanca. Protocolos, leg. 5186, f. 585r.

37 Jiménez percibió 60 reales por esta asistencia. Véase López Gómez, 1994, p. 33 y A.H.P. Salamanca. Protocolos, leg. 3315, f. 693 v y leg. 3445, f. 772 r. 
El hecho de que todos los médicos que ejercían en Salamanca estuvieran vinculados a su Universidad, influyó de manera decisiva en la asistencia sanitaria de la población. El fuerte control que ejercían sobre el mercado sanitario de la ciudad impidió que se dotaran plazas de médicos titulares, una reivindicación que los representantes del común plantearon en varias ocasiones a las autoridades municipales. Sin embargo la concentración del poder local en manos de una oligarquía de la que también formaban parte algunos de los catedráticos de Medicina, impidió la dotación de estas plazas ${ }^{38}$. Este monopolio del mercado sanitario se advierte también en el control de los honorarios que cobraban los facultativos por las visitas que realizaban. A través de un escrito presentado en 1793 por el Colegio de Médicos Doctorados de la Universidad al Ayuntamiento, sabemos que la minuta de estos facultativos ascendía a 20 reales para los vecinos «de medianas facultades», mientras que los pobres eran siempre visitados «de limosna». Una cantidad muy superior a la que percibían los médicos de Valencia o los de otras localidades españolas, que en ocasiones limitaban los honorarios que podían cobrar los facultativos para evitar situaciones de abuso (Granjel, 2009b, p. 5).

En 1793 las pretensiones de este colectivo de incrementar a 40 reales las tarifas por acto médico, originaron una encendida polémica en el seno del consistorio. Los representantes del común mostraron su oposición por las consecuencias que tenía para amplios sectores de la población, «a quienes se pretende obligar a que compren la salud por la tarifa asignada por este Cuerpo, que aspira a ser único, y sólo para sorberse los intereses de los pudientes, y chupar los cortos medios del pobre ${ }^{39}$. Aunque la pretensión fue rechazada por el consistorio, lo más interesante de esta polémica es la actitud de los dos personeros del común, muy críticos con el grupo de regidores que apoyaban los intereses de los profesores de Medicina. La vinculación de algunos «médicos graduados» con la oligarquía local, explica la firme voluntad de los representantes del común de «tomar a su cargo deshacer esta Liga», expresión que revela la existencia de estas alianzas. Unos vínculos reforzados por la condición universitaria de algunos regidores como Nicolás Rascón o Francisco Flores, ambos catedráticos en la Facultad de Cánones. Las redes tejidas al

38 La dotación de dos plazas de «médicos partidarios» se planteó por primera vez en 1784. Uno de los dos regidores encargados de informar al respecto fue José Ramón Vélez Cosío, que estaba casado con la hija del catedrático de Prima de Medicina Francisco Vélez de Cabiedes. Archivo Municipal de Salamanca (en adelante A.M.SA.). Actas de Sesiones, lib. 3055/169, ff. 128r-129v.

39 A.M.SA. Actas de Sesiones, lib. 3059/178, ff. 97v-98r. 
hilo de estos lazos familiares, académicos y sociales desempeñaron un papel decisivo en la defensa de los intereses de los catedráticos de Medicina y en el control que ejercieron sobre el mercado sanitario de la ciudad.

La dependencia de la economía salmantina del sector agrícola, se refleja en la forma de pago de los salarios y retribuciones de sus médicos. En 1753 sólo nueve de las 40 congregaciones religiosas que había en Salamanca sufragaban el importe de estas igualas en metálico. Muy similar es la situación registrada en los ajustes con los miembros de las élites locales, que a excepción del obispo, el corregidor y unas pocas familias, recurrieron también a los pagos en especie. Por lo que se refiere a los colegios mayores (San Bartolomé, Cuenca, Oviedo y el del Arzobispo), sólo el primero abonó el importe íntegro de los salarios en metálico ${ }^{40}$. Y entre los colegios menores sólo dos (el Trilingüe y el de la Magdalena) optaron por esta forma de pago. Por el contrario, las retribuciones en metálico fueron las utilizadas por los cuatro colegios militares y por la mayoría de los hospitales.

El Memorial remitido por Francisco Vélez de Cabiedes al Intendente de la provincia en cumplimiento de lo dispuesto en el Real Decreto de 1749 sobre la Única Contribución, permite ponderar la importancia de las retribuciones en especie. En esa fecha Vélez era catedrático de Vísperas y declaraba unos ingresos anuales de «319 fanegas de trigo, 111 fanegas de cebada y 1.902 reales» de su actividad asistencial ${ }^{41}$. Para Vélez de Cabiedes las retribuciones en especie representaban aproximadamente las tres cuartas partes de sus ingresos como médico, un porcentaje similar al de José Parada, Manuel Herrera Comán o Francisco Ovando.

Por este motivo los médicos guardaban en las paneras de sus casas importantes cantidades de trigo y cebada, que en ocasiones representaban sumas cuantiosas. Se comprueba en los inventarios practicados tras su muerte, en los que se recogían y tasaban todos sus bienes. A 1.068 reales ascendía el valor del grano que dejó Pedro San Martín cuando murió en 1743, el que guardaba Pedro Riaguas alcanzaba los 2.027 reales, el de Manuel Herrera Comán tenía un valor de 3.640 reales y el que dejaba Antonio Ballesteros importaba 3.570 reales. Sólo una parte se destinaba a cubrir las necesidades de la familia; el resto era siempre vendido, bien directamente por el facultativo o a través de

40 Una situación que no deja de ser significativa, pues el Colegio de San Bartolomé era la institución universitaria que encabezaba la relación del Mayor Hacendado de la provincia. Véase Robledo, Brel y Espinoza, 1994, p. 370.

41 A.H.P. Salamanca. Catastro de Ensenada. Libro de Relaciones de Seglares, leg. 2057, f. $338 \mathrm{v}$. 
terceras personas. En el inventario de bienes practicado tras la muerte de Francisco Ovando, se advierte que Matías Martín, médico de Cantalapiedra, le debía 50 fanegas de cebada «que tenía en su poder para venderlas» ${ }^{42}$.

Pero veamos cuál era el importe de estas igualas ${ }^{43}$. Como hemos indicado, los facultativos que regentaban las cátedras de propiedad acaparaban la asistencia de las congregaciones religiosas, hasta el punto de que sólo tres de las 40 comunidades que había en Salamanca (tanto masculinas como femeninas) fueron atendidas por el catedrático de Simples. La cuantía de sus retribuciones dependió tanto del número de miembros que tenía la comunidad y de su capacidad económica, como del prestigio del médico. Respecto a las congregaciones religiosas masculinas, el salario medio de los médicos fue de 122 reales anuales. La horquilla salarial osciló entre los 285 reales anuales que satisfacía el Convento de San Esteban a cada uno de sus dos facultativos (José Parada y Francisco Vélez) y los 49 reales que abonaba el Convento de Agustinos Recoletos a Francisco Vélez y a Juan Francisco González Cernuda por su asistencia. En el caso de las femeninas, el salario medio fue mayor (166 reales) y osciló entre los 330 reales que pagaba el Convento de las Comendadoras de Sancti Spiritus a Francisco Vélez y los 42 reales que recibía José Parada del Convento de Carmelitas descalzas.

Alcanzar la confianza de los «ricos o poderosos» suponía un reconocimiento explícito de prestigio y respetabilidad social, la mejor acreditación para aumentar la clientela. Ahora bien, convertirse en el médico de las principales familias nunca ha sido una tarea fácil, como tampoco lo fue para los catedráticos de Medicina de Salamanca que tuvieron que competir por esta asistencia. Como en el caso anterior, los titulares de las cátedras de propiedad monopolizaron la asistencia de las élites urbanas y aquí también la cuantía de sus retribuciones dependió tanto del número de miembros de la familia, como de su capacidad económica. Por la relevancia del cargo que ocupaban, el Obispo y el Corregidor fueron los que abonaron un salario más elevado (200 reales), cantidad que ambos satisfacían en metálico. En el resto de los casos las retribuciones oscilaron entre los 180 reales anuales que recibía Francisco Vélez de Francisco Nieto Botello, heredero del Conde de Monterrón y uno de los más destacados propietarios de la provincia, y los 28 reales anuales que abonaba Diego Rueda, miembro de la hidalguía salmantina, a José Parada. El

42 A.H.P. Salamanca. Protocolos, leg. 4198, f. 508v.

43 Toda esta información en A.H.P. Salamanca. Catastro de Ensenada. Libro de Relaciones de Seglares, leg. 2057, ff. 331r-345v; leg. 2058, ff. 134r-141r; leg. 2059, ff. 492r-495v y leg. 2060, ff. 608r-608v. 
trigo y la cebada fueron los frutos empleados por la mayoría de estas familias para satisfacer los salarios de los médicos.

En 1753 la clientela más selecta y acomodada la compartían José Parada (que ya estaba jubilado de su cátedra de Prima), Francisco Vélez, titular de la cátedra de Vísperas, y Manuel Herrera Comán, sucesor de Parada en la cátedra de Prima. El nivel de ingresos que obtenían por el ejercicio de su profesión les colocaba en una posición destacada con relación a sus compañeros de Facultad. A José Parada le estimaban una renta anual de 12.000 reales, a Francisco Vélez de 10.000 y a Manuel Herrera de 9.000 reales, cantidades que sólo incluían los salarios que percibían de la Universidad y el importe de las igualas con hospitales, comunidades y particulares ${ }^{44}$. Por este motivo, los funcionarios de la Real Junta de Única Contribución advertían que a estas cantidades «debe añadírsele la utilidad que tenga por otros encargos», indicación que hacía referencia a las ganancias obtenidas por las consultas y visitas médicas que realizaban. Una actividad difícil de fiscalizar y que resulta imposible estimar, dado que todos los médicos omitieron estas utilidades en las declaraciones de bienes que remitieron al Intendente de la Provincia. Como advierte Camarero, la tipología de intentos o casos de ocultación de información que se dio en las averiguaciones catastrales es muy amplia, una conducta fácil de entender en una operación donde averiguadores y averiguados defendían intereses enfrentados (Camarero Bullón, 2002, p. 519).

La extracción social de las familias que visitaban José Parada y Francisco Vélez revela el prestigio, respetabilidad y notabilidad pública que alcanzaron. Entre los pacientes eclesiásticos de Francisco Vélez figuraba el obispo José Zorrilla, el deán de la catedral y seis canónigos. Y entre su clientela seglar se encontraba el Corregidor José Pérez Mesía, la viuda del conde de Monterrey, Francisco Nieto Botello, Manuel Caballero (Comisario de Guerra de los Reales Ejércitos), Manuel García de la Cruz (abogado de los Reales Consejos y administrador del marqués de Coquilla) y varios regidores. Por su parte, José Parada tenía firmadas igualas con varias familias de la nobleza local (condesa de Canillas, el conde de Francos, el conde de Casasola, Bartolomé Joly, Diego Rueda) y con los regidores Luis de Paz, Blas de Lezo, José del Castillo,

44 Del resto de los médicos sólo Francisco Ovando, catedrático de Pronósticos, disfrutó de un mayor nivel de renta (8.100 reales). Por debajo se situaban los ingresos del catedrático de Método Juan Agustín de Medina (3.300 reales), del titular de Simples Juan Francisco González Cernuda (3.200 reales), del catedrático de Anatomía Pedro Ferrer (3.300 reales) y del presbítero Francisco Gómez, catedrático de Partido Mayor (3.000 reales). A juicio de los funcionarios del Catastro, su menor nivel de renta se debió a las «pocas visitas» que realizaban. 
Julián Rascón o Manuel Vela Girón ${ }^{45}$. La relevancia social de estas familias, pertenecientes a la nobleza local y a la burguesía de Antiguo Régimen, constituye un indicador de la ascendencia profesional y social de ambos facultativos. El prestigio académico de las cátedras que regentaban fue la llave de acceso al universo social de las élites, con las que generaron relaciones horizontales y verticales más o menos extensas y densas. Unos vínculos construidos sobre la base de redes clientelares y estrategias familiares, de gran importancia en el ascenso social de estos médicos.

\section{EL RESPALDO DEL HONOR}

En la sociedad del Antiguo Régimen no sólo importaba ser considerado miembro del grupo de las élites, sino también demostrarlo a través de los mecanismos existentes. Uno de estos medios fue el reconocimiento de hidalguía, condición que implicaba la pertenencia a un grupo social que, todavía en el siglo XVIII, disfrutaba de importantes privilegios. Como advierte Casey no bastaba con ser rico, era necesario añadir el respaldo del honor, situación que explicaría la preocupación de las élites por alcanzar la declaración oficial de su hidalguía (Casey, 2009, p. 54). Un interés en el que también influyó el deseo de emulación que se observa entre los grupos sociales emergentes, esa burguesía adinerada de Antiguo Régimen que buscó a través de estos títulos su vinculación a la nobleza.

Aunque los graduados en la Universidad de Salamanca disfrutaron de honores, derechos y privilegios que en alguna medida eran similares a los que tenía el estamento nobiliario, no impidió que los que gozaron de ascendencia hidalga solicitaran el reconocimiento de su estado y condición. La legitimación de la identidad noble y el valor añadido que confería un título, resultaban de gran utilidad para quienes buscaban una promoción social no exenta de dificultades. Ahora bien, si para los juristas que aspiraban a un oficio municipal o un cargo en la Administración el título suponía importantes beneficios, en el caso de los médicos los intereses fueron otros. Junto a las ventajas y privilegios que transmitían a sus descendientes, el reconocimiento formó parte de la estrategia diseñada para establecer contactos con los grupos de poder local y conseguir una integración social plena, entendida ésta como consolidación de una posición privilegiada.

45 A.H.P. Salamanca. Catastro de Ensenada. Libro de Relaciones de Seglares, leg. 2057, ff. $333 r-338 v$ y leg. 2058, ff. $134 v-138 r$. 
¿Hasta qué punto el reconocimiento de hidalguía fue un instrumento de ascenso, distinción y de relaciones sociales para un médico? El caso de la familia Joly permite comprobar la importancia de su condición hidalga, un estatus que favoreció el matrimonio de Bartolomé Joly de la Cruz (hijo del catedrático de Prima de Medicina Manuel Joly Orozco) con Ma Teresa de Pineda Maldonado, hija de un regidor perpetuo de Salamanca. El enlace culminó el ansia de reconocimiento social de la familia Joly y permitió a Bartolomé, del que su padre afirmaba que «nunca ha hecho pie constante, habiendo en mi casa gastado más que otro alguno», contar con los medios económicos suficientes para vivir sin trabajar.

El proceso seguido por Juan Francisco González Cernuda para alcanzar el reconocimiento de su condición hidalga, nos permite profundizar no sólo en los valores y mentalidad de una sociedad, sino también en el ámbito de los comportamientos y actitudes de un médico, su universo mental y en la visión que tuvo de su entorno y realidad. Juan Francisco era el segundo de los cinco hijos del matrimonio formado por Pedro González Suárez de Cernuda y María García de la Cuesta, ambos de condición hidalga. La trayectoria que siguieron los cinco hermanos fue la habitual entre los miembros de la pequeña nobleza: el primogénito permaneció toda su vida en Ordovaga al frente de la hacienda familiar; Juan Francisco siguió el camino de muchos segundones y fue enviado a estudiar a Salamanca, mientras que María, la única mujer, contraía matrimonio con un miembro de la pequeña nobleza asturiana. Los otros dos hermanos habían fallecido en edad temprana ${ }^{46}$.

En 1768 González Cernuda iniciaba los trámites legales ante la Real Chancillería de Valladolid, «para que en su virtud se me haga y tenga en esta Ciudad por Noble Hijodalgo, y guarden las preeminencias de tal». Este tipo de procesos se iniciaban cuando un hidalgo cambiaba de vecindad, pues aunque la Justicia y Corregimiento tuvieran conocimiento de su condición, no se daban por enterados. La situación obligaba al individuo a acreditar su linaje, para lo cual solicitaba de la Sala de Hijosdalgos que se formara el oportuno expediente. Entre 1767 y 1768 se realizaron las denominadas «probanzas» en Salamanca y en su localidad natal y en mayo de 1769 se firmaba la Real Provisión. Al poco tiempo se recibía en el Ayuntamiento de Salamanca la ejecutoria expedida por la Sala de Hijosdalgos «en que se manda se le reconozca por tal Hijodalgo al Dr. D. Juan Francisco González Cernuda del Gremio y Claustro de esta Universidad» ${ }^{47}$.

46 Toda la información relativa a la familia González Cernuda y el proceso de hidalguía en ARCHV. Sala de Hijosdalgo. Caja 1136.0041.

47 A.M.SA. Actas de Sesiones, lib. 3048/154, f. 194r. 
Lo primero que llama la atención es el momento en que González Cernuda decidió acreditar su condición de hidalgo. En esa fecha (abril de 1767) acababa de fallecer su segunda mujer y carecía de descendencia, por lo que en su caso la solicitud no se hacía por un deseo de transmisión del linaje. Además, por su condición de graduado por la Universidad de Salamanca disfrutaba de los honores y privilegios que tenían «los demás individuos de su Gremio y Claustro (...), sin haber jamás contribuido ni pechado con aquellos pechos y contribuciones del estado llano», circunstancia que excluye motivos de esta índole. Cabría pensar en la perspectiva de un nuevo enlace con una mujer de la oligarquía local, aunque no debió ser ese el motivo pues hasta 1776 no contrajo nuevas nupcias.

En el trasfondo de su decisión se vislumbra no sólo sus deseos de presunción y cierto grado de vanagloria («para que se me den y guarden dichas prerrogativas»), sino también la necesidad de afianzar a través de su promoción social una carrera profesional no exenta de dificultades. Ya nos hemos referido a los problemas que tuvo en el seno de la Universidad, un comportamiento que también afecto a su actividad asistencial. Cuando en 1781 quedó vacante la plaza de médico del Hospital del Estudio, el claustro de diputados eligió por mayor número de votos a Antonio Cuesta. La designación del catedrático de Vísperas frente a la tradición de nombrar al titular de Prima, que en esa fecha era González Cernuda, pone de relieve las dificultades mencionadas ${ }^{48}$.

Para González Cernuda el reconocimiento de hidalguía fue ante todo un instrumento de distinción social y de integración en la oligarquía salmantina. El interés por acreditar su linaje es muy indicativo del peso que tuvo la nobleza como grupo dirigente $\mathrm{y}$, muy especialmente, su grado de influencia para otros grupos sociales, deseosos de compartir con ella una misma posición y una misma forma de vida.

\section{CONCLUSIÓN}

En este trabajo hemos querido poner de manifiesto la riqueza documental de los protocolos notariales, actas capitulares y documentación académica para el análisis social de la profesión médica. Lo interesante de conjugar las biografías de estos individuos con el estudio de las redes sociales, es comprobar cómo

48 La plaza de médico del Hospital del Estudio fue siempre ocupada por el catedrático de Prima. A lo largo del siglo XVIII José Colmenero, Pedro Carrasco, Pedro San Martín, José Parada, Francisco Vélez y Antonio Cuesta fueron los facultativos que desempeñaron esta asistencia. Véase Santander, 1993, pp. 148-152. 
se relacionan entre sí y el tipo de vínculos que establecen con personas de un estatus social superior. Unas relaciones de gran importancia para alcanzar oportunidades, recursos, influencia y poder. Pensamos que acercamientos de este tipo permitirán superar los análisis clásicos, establecidos a partir de roles y atributos muchas veces reduccionistas, y explicar mejor la verdadera identidad social de este colectivo. Se trata de una nueva aproximación a un tema en el que seguimos trabajando, por lo que los aspectos que no hemos podido desarrollar son muchos, cuestiones que quedan para nuevos trabajos.

\section{BIBLIOGRAFÍA}

Ariès, Philippe (2000), Historia de la muerte en Occidente desde la Edad Media hasta nuestros días, Barcelona, El Acantilado, pp. 177-191.

Cabo Alonso, Ángel (1992), "Salamanca en el siglo XVIII". En: Actas I Congreso Historia de Salamanca. Tomo I, Salamanca, Diputación de Salamanca, pp. 61-86, p. 64.

Camarero Bullón, Concepción (2002), "Averiguarlo todo de todos: el Catastro de Ensenada", Estudios Geográficos, 63 (248-249), pp. 493-531, p. 519, [en línea], disponible en: http://estudiosgeograficos.revistas.csic.es/index.php/estudiosgeograficos/article/view/ 236/235, [consultado el 30-04-2012]

Carreras Panchón, Antonio (2006), "La Medicina, siglos XVI-XIX”. En: Rodríguez-San Pedro Bezares, Luis E. (coord.), Historia de la Universidad de Salamanca. III.1. Saberes y confluencias, Salamanca, Universidad de Salamanca, pp. 303-344, p. 318.

Casey, James (2009), "Los ciudadanos de Granada, 1570-1739: Familia y sociedad en la España moderna". En: Soria Mesa, Enrique; Bravo Caro, Juan Jesús; Delgado Barrado, José Miguel (eds.), Las élites en la Época Moderna: La monarquía española. Vol. 1. Nuevas perspectivas, Córdoba, Universidad de Córdoba, pp. 47-58, pp. 54 y 56.

Cook, Harold J. (1986), The decline of the Old Medical Regime in Stuart England, Ithaca (N.Y.), Cornell University Press, pp. 19-28.

Eiras Roel, Antonio (1981), "Tipología documental de los protocolos gallegos". En: La historia social de Galicia en sus fuentes de protocolos, Santiago de Compostela, Universidad de Santiago, pp. 21-113, p. 64.

Eiras Roel, Antonio (1984), "Las élites urbanas de una ciudad tradicional: Santiago de Compostela a mediados del siglo XVIII". En: La documentación notarial y la historia. Actas del II Coloquio de Metodología Histórica Aplicada, Santiago de Compostela, Universidad de Santiago, pp. 117-139, pp. 119-121.

Gómez Navarro, Soledad (2000), "Una función fundamental: el albaceazgo en una comunidad de la Edad Moderna", Obradoiro de Historia Moderna, 9, pp. 171-188, p. 177.

Granjel, Mercedes (2009a), "Médicos y élites locales en la sociedad extremeña del siglo XVIII", Llull, 32 (70), pp. 317-346.

Granjel, Mercedes (2009b), "Ser médico en la España del siglo XVIII", Medicina e Historia. Cuarta Época, 3, pp. 1-16. 
Grecenková, Martina (2004), "L'itinéraire professionnel et l'univers intellectuel des bureaucrates éclairés", Histoire, Economie \& Société, 23 (4), pp. 503-524, pp. 505-506, [en línea], disponible en: http://www.persee.fr/web/revues/home/prescript/article/hes_0752-5702_ 2004, [consultado el 14-05-2012]

Imízcoz Beunza, José $M^{a}$ (1996), “Comunidad, red social y élites. Un análisis de la vertebración social en el Antiguo Régimen”. En: Imízcoz Beunza, José Ma (coord.), Élites, poder y red social. Las élites del País Vasco y Navarra en la Edad Moderna (Estado de la cuestión y perspectivas), Bilbao, Universidad del País Vasco, pp. 13-50, pp. 39-40.

Imízcoz Beunza, José Ma (2009), "Las redes sociales de las élites. Conceptos, fuentes y aplicaciones". En: Soria Mesa, Enrique; Bravo Caro, Juan Jesús; Delgado Barrado, José Miguel (eds.), Las élites en la Época Moderna: La monarquía española. Vol. 1. Nuevas perspectivas, Córdoba, Universidad de Córdoba, pp. 77-111, p. 82.

Lilao Franca, Óscar; Castrillo González, Carmen (1997), Catálogo de manuscritos de la Biblioteca Universitaria de Salamanca. I. Manuscritos 1-1679bis, Salamanca, Universidad de Salamanca, p. 208.

López Gómez, José Manuel (1994), Sociología de las profesiones sanitarias en Mérida (1700-1833), Barcelona, PPU, p. 33.

Martínez Millán, José (1992), “La investigación sobre las élites de poder”. En: Martínez Millán, José (ed.), Instituciones y élites de poder en la Monarquía hispánica durante el siglo XVI, Madrid, Universidad Autónoma, pp. 11-24, pp. 21-22.

Maruri Villanueva, Ramón (1998), "La sociedad urbana". En: Morales Moya, Antonio (coord.), Historia de España Menéndez Pidal. XXX. Las bases políticas, económicas y sociales de un régimen en transformación (1759-1834), Madrid, Espasa Calpe, pp. 715-789, p. 748.

Olagüe de Ros, Guillermo (2005), "De las vidas ejemplares a las biografías colectivas de los médicos. Una perspectiva crítica", Asclepio, 67 (1), pp. 135-148, pp. 145-146, [en línea], disponible en: http://asclepio.revistas.csic.es/index.php/asclepio/issue/view/4 [consultado el 20-04-2012]

Pardo Tomás, José; Martínez Vidal, Àlvar (2005), "Presencias y silencios. Biografías de médicos en el Antiguo Régimen”, Asclepio, 67 (1), pp. 55-66, pp. 57-58, [en línea], disponible en: http://asclepio.revistas.csic.es/index.php/asclepio/issue/view/4 [consultado el 20-04-2012]

Peset, Mariano; Peset, José Luis (1969), El reformismo de Carlos III y la Universidad de Salamanca: Plan general de estudios dirigido a la Universidad de Salamanca por el Real y Supremo Consejo de Castilla en 1771, Salamanca, Universidad de Salamanca, pp. 38-40.

Pomata, Gianna (1998), Contracting a Cure. Patients, healers and the law in Early Modern Bologna, Baltimore, Johns Hopkins University Press, p. 121.

Pro Ruiz, Juan (1995), "Las élites de la España liberal: Clases y redes en la definición del espacio social (1808-1931)", Historia Social, 21, pp. 47-69, p. 49.

Ramsey, Matthew (1988), Professional and popular medicine in France, 1770-1830. The social world of medical practice, Cambridge, Cambride University Press, pp. 55-56. 
Rieder, Philip (2005), "Médecins et patients à Geneve: offre et consommations thérapeutiques à l'époque moderne", Revue d'Histoire Moderne et Contemporaine, 52 (1), pp. 39-63, pp. 42-46.

Robledo, Ricardo; Brel, Ma Pilar; Espinoza, Luis Enrique (1994), "El Mayor Hacendado en la provincia de Salamanca (1753)", Salamanca Revista de Estudios, 33-34, pp. 361-412, p. 370.

Rodríguez-San Pedro Bezares, Luis Enrique; Polo Rodríguez, Juan Luis (2004), "Cátedras y catedráticos: Grupos de poder y promoción, siglos XVI-XVIII". En: Rodríguez-San Pedro Bezares, Luis Enrique (coord.), Historia de la Universidad de Salamanca. II. Estructuras y flujos, Salamanca, Universidad de Salamanca, pp. 767-801, pp. 786-787.

Rodríguez-San Pedro Bezares, Luis Enrique; Polo Rodríguez, Juan Luis; Alejo Montes, Francisco Javier (2004), "Matrículas y grados. Siglos XVI-XVIII". En: RodríguezSan Pedro Bezares, Luis Enrique (coord.), Historia de la Universidad de Salamanca. II. Estructuras y flujos, Salamanca, Universidad de Salamanca, pp. 607-663, pp. 653658.

Santander, Teresa (1993), El Hospital del Estudio, Salamanca, Centro de Estudios Salmantinos, pp. 148-152.

Shapin, Steven; Thackray, Arnold (1974), "Prosopography as a research tool in History of Science", History of Science, 12 (15), pp. 1-28, p. 4.

Stone, Lawrence (1986), El pasado y el presente, México, Fondo de Cultura Económica, p. 61.

Townsend, Joseph (1988), Viaje por España en la época de Carlos III (1786-1787), Madrid, Turner, p. 407.

Recibido: 27 de mayo de 2011

Aceptado: 20 de agosto de 2011 